\title{
Uso da flora em assentamento agroextrativista do litoral de Sergipe, Brasil
}

\author{
Use of flora in agroextrativist seating of the coast of Sergipe, Brazil
}

\author{
Débora Moreira de Oliveira ${ }^{1}$ \\ Luiz Aquino Silva Santos ${ }^{2}$ \\ Laura Jane Gomes ${ }^{3}$
}

\begin{abstract}
Resumo
Este trabalho objetivou analisar o conhecimento que os moradores do Projeto de Assentamento Agroextrativista (PAE) São Sebastião possuem dos recursos florísticos do local, por meio das ferramentas utilizadas na etnobotânica. A área de estudo encontra-se no domínio de restinga, na zona rural da cidade de Pirambu, litoral norte de Sergipe, onde estão assentadas 28 famílias que desenvolvem atividades econômicas diretamente relacionadas aos recursos naturais, fato que garantiu o enquadramento do assentamento na modalidade diferenciada denominada "agroextrativista", a saber: extrativismo dos frutos da mangabeira (Hancornia speciosa Gomes), artesanato com palha de ouricurizeiro (Syagrus coronata Martius Beccari) e agricultura familiar. Foram realizadas 39 entrevistas com auxílio de formulário semiestruturado. Os entrevistados citaram 162 nomes populares de plantas úteis, que resultaram na coleta e identificação de 90 espécies classificadas em 46 famílias botânicas, sendo as mais representativas Leguminosae (11), Myrtaceae (6) e Arecaceae (6), depositadas no Herbário da Universidade Federal de Sergipe (ASE). As categorias de uso com maior número de citações foram Medicinal (45) e Alimentícia (44). A maioria das espécies é nativa do Brasil $(65,9 \%)$ e os três maiores valores de uso (VU) estiveram associados a elas, atribuídos para as espécies ouricurizeiro $(S$. coronata, $\mathrm{VU}=1,38)$, macaxeira/mandioca (Manihot esculenta, $\mathrm{VU}=0,89$ ) e mangabeira $(H$. speciosa, $\mathrm{VU}=0,87)$, confirmando que desempenham um importante papel para a subsistência e complementação da renda familiar. Os resultados da pesquisa demonstram que o potencial extrativista, objetivo da modalidade diferenciada de assentamento, ainda pode ser melhor explorado através da valorização do conhecimento dos assentados.
\end{abstract}

Palavras-chave: Etnobotânica. Extrativismo. Recursos florísticos. Produtos florestais não madeireiros.

\begin{abstract}
This work aimed to analyze the knowledge that the residents of the Projeto de Assentamento Agroextrativista (PAE) São Sebastião have of the floristic resources of the place, through the tools used in Ethnobotany. The study area is located in the restinga area, in the rural area of the city of Pirambu, in the north coast of Sergipe, where 28 families are established that carry out economic activities directly related to natural resources, a fact that guaranteed the setting of the settlement in the differentiated modality called "agroextractivist", namely: extractivism of mangabeira fruits

\footnotetext{
${ }^{1}$ Doutoranda no Programa de Pós-Graduação em Desenvolvimento e Meio Ambiente da Universidade Federal de Sergipe. E-mail: d.oliveira.doc@gmail.com

${ }^{2}$ Graduado em Ciências Biológicas Lic. Pela Universidade Federal de Sergipe. E-mail: luizaquino_1989@hotmail.com

${ }^{3}$ Professora dos Programas de Pós-Graduação em Desenvolvimento e Meio Ambiente (PRODEMA) e Recursos Hídricos (PRORH) da Universidade Federal de Sergipe. E-mail: laurabuturi@gmail.com
} 
(Hancornia speciosa Gomes), handicrafts with straw of ouricurizeiro (Syagrus coronata Martius Beccari) and family farming. A total of 39 interviews were conducted using a semistructured form. The interviewees cited 162 popular names of useful plants, which resulted in the collection and identification of 90 species classified in 46 botanical families, the most representative being Leguminosae (11), Myrtaceae (6) and Arecaceae (6) deposited in the herbarium of the Universidade Federal de Sergipe (ASE). The categories of use with the greatest number of citations were Medicinal (45) and Food (44). The majority of the species were native to Brazil (65.9\%) and the three highest values of use $(\mathrm{VU})$ were associated with them, attributed to the species coriacea $(S$. coronata, $\mathrm{VU}=$ 1,38), macaxeira/mandioca (Manihot esculenta, $\mathrm{VU}=0.89)$ and mangabeira $(H$. speciosa, $\mathrm{VU}=$ 0.87), confirming that they play an important role for the subsistence and complementation of family income. The results of the research demonstrate that the extractive potential, objective of the differentiated modality of settlement, can still be better exploited through the valuation of the knowledge of the settlers.

Keywords: Ethnobotany. Extractivism. Floristic resources. Non-timber forest products.

\section{Introdução}

No Brasil, os ecossistemas litorâneos têm sido alvo de degradação desde os primórdios da colonização europeia. No estado de Sergipe a pressão antrópica concentra-se principalmente sobre as áreas litorâneas, atingindo, em toda a sua extensão, as áreas de ecossistemas associados à Mata Atlântica, como Manguezais, Sistemas Dunares e Restingas. Segundo Souza e Oliveira (2006), a ocupação do litoral tem se intensificado devido à especulação imobiliária baseada nas belezas singulares da região, que, em conjunto com a expansão urbana e o estímulo ao turismo sem planejamento prévio, têm se configurado como as principais ações impactantes do litoral sergipano.

$\mathrm{O}$ enfoque deste trabalho encontra-se em ecossistema de restinga, legalmente reconhecido como área protegida (BRASIL, 2006). No litoral norte de Sergipe, particularmente nos municípios de Pirambu e Pacatuba, a faixa coberta pela vegetação de restinga pode alcançar cerca de $10 \mathrm{~km}$ de largura, estando localizada logo após a estreita associação entre praias e dunas (PORTO, 1999).

Desse modo, reconhecendo que tal ecossistema é um ambiente que tem sofrido intensas pressões, o Governo Federal brasileiro, por meio do IBAMA, instituiu em $45 \mathrm{~km}$ da costa pertencentes às cidades de Pacatuba e Pirambu a Reserva Biológica (REBio) Santa Isabel (BRASIL, 1988), categoria de unidade de conservação de Proteção Integral que restringe a interferência humana com o objetivo de preservar a biota e os atributos naturais da região de instalação, limitando-a à ações de recuperação e manejo essenciais para restaurar o equilíbrio natural ecossistêmico (BRASIL, 2000).

No ano de 2006, após pressão de assentados vinculados ao Movimento dos Trabalhadores Rurais Sem Terra (MST), foi implantado, nas proximidades da REBio de Santa Isabel, o Projeto de 
Assentamento Agroextrativista São Sebastião (PAE São Sebastião), único no estado que se enquadra nessa modalidade, que busca minimizar os impactos humanos sobre o ecossistema e, ao mesmo tempo, proporcionar uma base econômica sustentável. A criação desse assentamento se justificou pelo fato das terras da Fazenda Santa Isabel, que foi desapropriada, já serem espaço de vida e trabalho de moradores que desenvolviam atividades agroextrativistas e, ainda, por estes estarem inseridos em uma área com grandes restrições agropecuárias tanto no caráter de proteção legal, por ser remanescente de Mata Atlântica e pela proximidade da REBio Santa Isabel, quanto pela própria característica do solo, que traz limitações de uso.

Ainda que algumas medidas tenham sido tomadas em prol da proteção do meio ambiente e do desenvolvimento social na região, prevalece a antiga dualidade entre desenvolvimento rural e meio ambiente, que tem gerado conflitos sobre como orientar as atividades em um assentamento de caráter agroextrativista, de modo que a consolidação da proposta vem sendo comprometida. Isso coloca em risco a vegetação nativa local, pois mesmo a vegetação nativa tendo potencial para gerar recursos de importância econômica, existem outras formas de uso desses espaços que garantem "retornos financeiros maiores e mais rápidos para os que promovem o desmatamento" (PEREIRA, 2008, p. 196).

A realidade encontrada é que a pressão vinda das mudanças em andamento na região litorânea tem dificultado cada vez mais o acesso das populações locais do litoral sergipano aos recursos extrativistas. É preciso reconhecer e manter o conhecimento complexo sobre os ecossistemas e a biodiversidade associada que as comunidades locais construíram (CASTRO, 2000) para que este possa somar-se ao conhecimento científico, de modo a promover melhorias futuras para a população, como a busca pela autossuficiência alimentar, inserção no mercado regional e conservação do ambiente.

A etnobotânica é uma ciência que se preocupa em entender a inter-relação direta entre pessoas de culturas viventes e as plantas de seu meio, aliando tanto fatores culturais quanto ambientais para entender as concepções dessas culturas sobre as plantas e o aproveitamento dado a elas (ALBUQUERQUE, 2002). Assim, essa disciplina estuda uma das principais relações dos seres humanos com o meio e tem papel fundamental nos temas relacionados à conservação de espécies, desenvolvimento sustentável e sustentabilidade, sendo necessário que os pesquisadores que se utilizam de seus preceitos e técnicas saibam valorizar o conhecimento tradicional, entendendo que as alternativas de desenvolvimento devem ser compreendidas como um conjunto de medidas que permitam colocar em prática projetos que reconheçam o saber nativo (ALMEIDA, 2004). 
Nesse contexto, entende-se que a criação de uma modalidade especial de assentamento para assentados que em sua maioria residem na região há pelo menos duas gerações tem o potencial de subsidiar a valorização do conhecimento popular associado aos recursos naturais locais, estimulando o debate sobre o manejo e a sustentabilidade destes. Com isso, o objetivo deste estudo consistiu em, por meio das ferramentas utilizadas na etnobotânica, analisar o conhecimento que os moradores do PAE São Sebastião possuem dos recursos florísticos, a fim de fornecer subsídios para a gestão dos recursos florísticos em bases sustentáveis, respeitando e valorizando o conhecimento construído ao longo das relações homem-natureza na região.

\section{Material e métodos}

O Assentamento Agroextrativista São Sebastião ocupa uma área contígua ao povoado Alagamar, pertencente ao município de Pirambu, litoral norte de Sergipe, nordeste brasileiro. A área está inserida na Sub-Bacia do Rio Betume, que é o principal tributário da Bacia do Rio São Francisco na região mais próxima ao litoral sergipano, obtida através da desapropriação de 610,312 hectares da antiga Fazenda Santa Isabel, tendo sua regulamentação efetiva em 08/07/2006 (PEREIRA, 2008). A vegetação nativa da área é parte do bioma Mata Atlântica, mais especificamente a Floresta de Tabuleiros, que é o terceiro grande corpo florestal brasileiro. Ocorre na forma de uma estreita faixa litorânea, de abrangência entre os estados de Pernambuco e Rio de Janeiro, e que comportam a restinga sobre as alvas areias quaternárias (RIZZINI, 1997).

A pesquisa ocorreu do mês de fevereiro a dezembro de 2011. No início desse período, os participantes foram apresentados à proposta do projeto e, a partir da aceitação, solicitados a assinar o Termo de Consentimento Livre e Esclarecido (TCLE), conforme orientações da legislação específica e do código de ética da Sociedade Internacional de Etnobiologia (BRASIL, 1996; ISE, 2006). Como a pesquisa investigou os saberes relacionados à flora de todos os moradores do assentamento, optou-se em entrevistar todos os homens e mulheres responsáveis por cada lote que concordassem em participar da pesquisa, que foram identificados por uma letra (" $\mathrm{H}$ " para homens e " $\mathrm{M}$ " para mulheres) e um número, atribuído pela ordem de realização das entrevistas semiestruturadas.

As entrevistas inicialmente acessaram os aspectos socioeconômicos da família e, em seguida, o informante foi convidado a listar todas as plantas úteis das quais se recordava, e não necessariamente utilizava, obtendo-se assim os nomes populares das espécies úteis à comunidade. Durante a listagem o entrevistado foi também convidado a enquadrar as plantas úteis de acordo com 
seis categorias de uso previamente estabelecidas, a saber: medicinal, alimentícia, místico/religioso, artesanal, ornamental, madeireiro e outros usos. Os resultados obtidos especificamente para o uso madeireiro foram publicados em Oliveira, Santos e Gomes (2013).

Para a análise das entrevistas foram empregadas técnicas de caráter qualitativo e quantitativo, pois conforme Amorozo e Viertler (2010), são análises que se complementam, pois constituem "aspectos diferentes de uma mesma realidade" (p. 74). Assim, foram utilizadas técnicas quantitativas específicas a estudos etnobotânicos como o cálculo do Valor de Uso (obtido pela fórmula $\mathrm{VU}=\sum \mathrm{U} / \mathrm{n}$, que expressa o valor de uso que uma espécie tem para a comunidade estudada através da razão entre o somatório do número de usos mencionados por cada informante "U" e o número total de informantes “n”) (SILVA et al., 2010), bem como a análise qualitativa através da compilação de dados em gráficos e tabelas, para melhor organização e visualização de dados com o fim de permitir a reflexão sobre eles.

A segunda etapa da pesquisa ocorreu nas áreas dos quintais, roças (lotes) e na mata, quando foram percorridas trilhas pré-construídas pelos moradores através do emprego da técnica de Turnê Guiada (ALBUQUERQUE; LUCENA; ALENCAR, 2010), tanto a pé quanto em montarias, num primeiro momento, a fim de conhecer as áreas utilizadas para coleta de material botânico, e, num segundo momento, com o fim de coletar as espécies citadas que se encontravam disponíveis apenas nos remanescentes florestais. Os cinco moradores que participaram das coletas de espécies através de turnê guiada foram selecionados mediante dois critérios: demonstração de conhecimento sobre a flora local através da análise da primeira entrevista e disponibilidade em acompanhar a coleta in loco do material botânico.

No mínimo dois exemplares de cada espécime foram coletados, tomando-se as precauções necessárias para a conservação do material e o preparo de exsicatas conforme descrito por Santos et al. (2010). O material foi registrado e incorporado ao Herbário da Universidade Federal de Sergipe ASE, bem como classificado de acordo com sua origem como espécie Nativa (N), Naturalizada (Nat), Cultivada (C) ou Não Ocorre (NO), em relação ao Brasil (REFLORA, 2015). Foi ainda verificado, de acordo com o relato dos entrevistados, a ocorrência de todas as espécies na área do assentamento em relação a seu plantio, isto é, buscou-se compreender quais espécies estão "naturalmente" presentes no assentamento (tanto pela ocorrência espontânea das espécies nativas na região quanto pela presença devido a cultivos anteriores ao assentamento) e quais são cultivadas pelos assentados ou não. 


\section{Resultados e discussão}

\section{$\underline{\text { I. Caracterização da comunidade e dos entrevistados }}$}

Os resultados da primeira etapa da entrevista indicam que as atividades realizadas no PAE São Sebastião ocorrem basicamente em três locais, ou zonas de recursos, distintos: o núcleo urbano, as roças e a mata. O núcleo urbano apresenta uma rua central, ao redor da qual se encontram dispostas 30 áreas de $2000 \mathrm{~m}^{2}$ (20 x 100), onde se localizam as residências dos assentados e seus respectivos quintais. Inicialmente, o projeto de assentamento abrangia trinta famílias, contudo, atualmente apenas 28 dessas áreas habitacionais encontram-se ocupadas por assentados. Durante a pesquisa, 19 homens e 20 mulheres se dispuseram a participar, totalizando 39 entrevistados, e abrangendo pelo menos um morador de cada uma das 28 famílias do PAE São Sebastião.

Cada uma dessas famílias possui ainda uma área de roça exclusiva, delimitada no momento da implementação do assentamento, de cerca de 2,3 ha. Essas áreas são denominadas pelos assentados como "lotes", sendo cada um livre para administrar a área de acordo com as necessidades e interesses familiares. Os plantios mais encontrados são: coqueirais (Cocos nucifera), bananais (Musa paradisiaca), milharais (Zea mays) e leiras de mandioca/macaxeira (Manihot esculenta). O restante da área do assentamento é de uso comum dos assentados, em regiões denominadas globalmente como "mata", que compõe diversos tipos de fitofisionomias características. Na mata são realizados extrativismo vegetal e também caça e pesca.

Foi investigada a origem dos moradores maiores de 18 anos, o que levou à percepção de que a origem da comunidade está claramente vinculada ao povoado Alagamar (17 homens e 12 mulheres), vizinho ao assentamento, e ao município de Pacatuba (11 homens e quatro mulheres), que faz fronteira com o município de Pirambu. O fato de os assentados do PAE São Sebastião já serem moradores da região antes da reivindicação de posse da terra atende satisfatoriamente à proposta de Assentamentos Agroextrativistas, visto que visam atender às populações extrativistas locais já presentes em determinada região. Apenas seis pessoas (três homens e três mulheres) vieram de outros estados do país e os demais (dois homens e quatro mulheres) de outros municípios do estado de Sergipe.

As principais fontes de subsistência e/ou renda das famílias são os produtos oriundos das roças/lotes (28 famílias citaram, 100\%), artesanato com palha de ouricurizeiro (20, 71,5\%, Syagrus coronata), mangaba $(15,53,5 \%$, Hancornia speciosa), farinha de mandioca/macaxeira $(12,43 \%$, M. esculenta) e pesca $(9,32 \%)$. Outras atividades também foram citadas, porém por apenas sete 
famílias, entre as quais: trabalho em fazendas (retirada de coco), venda de gêneros alimentícios (minimercado) e trabalho esporádico como pedreiro e "arrumadeira".

Todos os entrevistados reconheceram que a venda do artesanato a partir da palha do ouricurizeiro ( $S$. coronata) é atividade essencial para a renda das famílias, bem como a comercialização do fruto da mangabeira (H. speciosa). Nas oito famílias em que as mulheres não mais faziam o artesanato não foi por não saberem a arte, mas por motivos como idade avançada e problemas de visão; por sua vez, as 13 famílias que não mais coletam mangaba justificaram que deixaram a atividade pela grande distância que é necessário andar para buscá-las, pois após o sorteio dos lotes, muitas famílias foram contempladas com áreas que possuem muitos pés de mangabeira enquanto outras não têm nenhum. Sobre a farinha de mandioca e a pesca, os entrevistados afirmaram que são basicamente para o sustento da família, sendo pouca ou nenhuma a quantidade que é vendida. No caso da pesca, apenas uma família afirmou que comercializa o recurso.

Ressalta-se que a exploração dos recursos tanto extrativos quanto cultivados é notadamente sazonal e que essa periodicidade de recursos muitas vezes pode levar até mesmo à extinção da espécie se a pressão de uso sobre o recurso for grande. No caso da mangabeira (H. speciosa), por exemplo, os moradores que ainda realizam a coleta dos frutos afirmaram que retiram todos aqueles viáveis (que estão "apaé", expressão usada regionalmente para indicar que o fruto está em um estágio entre a imaturação e maturação completa), o que pode gerar um desequilíbrio na taxa de recuperação da espécie.

\section{$\underline{\text { II. Conhecimento e uso da flora regional }}$}

Os moradores citaram 162 nomes populares de plantas úteis que, após a identificação botânica, resultaram em 90 espécies. A diferença entre o número de nomes populares citados para plantas úteis e o número de espécies identificadas justifica-se tanto pelo fato de, muitas vezes, dois ou mais nomes populares corresponderem a apenas uma espécie quanto pela ausência de floração e frutificação no período do estudo, que impossibilitou o depósito de parte do material coletado no herbário.

As 90 espécies identificadas pertencem a 46 famílias botânicas e a 83 gêneros (Tabela 1). Destas, 59 (65,6\%) são nativas do Brasil, 14 (15,6\%) são naturalizadas, 9 (10\%) não ocorrem no país e $8(8,8 \%)$ são cultivadas. As famílias botânicas mais representativas foram Leguminosae (11), Myrtaceae (6) e Arecaceae (6), também em evidência em outros estudos em áreas de restinga (FONSECA-KRUEL; PEIXOTO, 2004; GANDOLFO; HANAZAKI, 2011; MELO; LACERDA; HANAZAKI, 2008). 
TABELA 1 - LISTA DE ESPÉCIES ÚTEIS INDICADAS PELOS MORADORES DO ASSENTAMENTO SÃO SEBASTIÃO, PIRAMBU, SERGIPE

\begin{tabular}{|c|c|c|c|c|c|c|c|c|}
\hline Família & Espécie & Nome Popular & Categoria(s) & NC & Ori & Oc & $\mathbf{V U}$ & ASE \\
\hline Acanthaceae & Justicia sp. & vence tudo & $\mathrm{O}$ & 1 & $\mathrm{~N}$ & $\mathrm{Ca}$ & 0,03 & 22081 \\
\hline Adoxaceae & $\begin{array}{l}\text { Sambucus australis } \\
\text { Cham. \& Schltdl. }\end{array}$ & sabugo & MD & 3 & $\mathrm{~N}$ & $\mathrm{Ca}$ & 0,10 & 20494 \\
\hline Amaranthaceae & $\begin{array}{l}\text { Alternanthera brasiliana } \\
\text { (L.) Kuntze } \\
\text { Pfaffia glomerata } \\
\text { (Spreng.) Pedersen } \\
\text { Chenopodium } \\
\text { ambrosioides L. }\end{array}$ & $\begin{array}{l}\text { amoxilina } \\
\text { anador } \\
\text { mastruz }\end{array}$ & $\begin{array}{l}\text { MD } \\
\text { MD } \\
\text { MD }\end{array}$ & $\begin{array}{l}4 \\
3 \\
11\end{array}$ & $\begin{array}{l}\mathrm{N} \\
\mathrm{N} \\
\mathrm{Nat}\end{array}$ & $\begin{array}{l}\mathrm{Ca} \\
\mathrm{NCa} \\
\mathrm{NCa}\end{array}$ & $\begin{array}{l}0,18 \\
0,10 \\
0,46\end{array}$ & $\begin{array}{r}21169 \\
23004 \\
20484\end{array}$ \\
\hline Anacardiaceae & $\begin{array}{l}\text { Schinus terebinthifolius } \\
\text { Raddi } \\
\text { Anacardium occidentale } \\
\text { L. } \\
\text { Mangifera indica } \mathrm{L} \text {. } \\
\text { Spondias purpurea } \mathrm{L} \text {. }\end{array}$ & $\begin{array}{l}\text { aroeira } \\
\text { caju } \\
\text { manga } \\
\text { siriguela }\end{array}$ & $\begin{array}{l}\text { MD } \\
\text { AL, MD } \\
\text { AL } \\
\text { AL }\end{array}$ & $\begin{array}{l}1 \\
14 \\
27 \\
2\end{array}$ & $\begin{array}{l}\mathrm{N} \\
\mathrm{N} \\
\mathrm{C} \\
\mathrm{NO}\end{array}$ & $\begin{array}{l}\mathrm{NCa} \\
\mathrm{Ca}, \mathrm{NCa} \\
\mathrm{Ca}, \mathrm{NCa} \\
\mathrm{Ca}\end{array}$ & $\begin{array}{l}0,05 \\
0,36 \\
0,69 \\
0,05\end{array}$ & $\begin{array}{l}22079 \\
20486 \\
21162 \\
21153\end{array}$ \\
\hline Annonaceae & $\begin{array}{l}\text { Xylopia laevigata } \\
\text { (Mart.) R.E. Fr. }\end{array}$ & araticum cagão & MD & 2 & $\mathrm{~N}$ & $\mathrm{NCa}$ & 0,05 & 22085 \\
\hline Apocynaceae & $\begin{array}{l}\text { Hancornia speciosa } \\
\text { Gomes } \\
\text { Catharanthus roseus (L.) } \\
\text { G. Don }\end{array}$ & $\begin{array}{l}\text { mangaba } \\
\text { boa noite/bom dia }\end{array}$ & $\begin{array}{l}\text { AL, MD } \\
\text { OR, MD }\end{array}$ & $\begin{array}{l}31 \\
5\end{array}$ & $\begin{array}{l}\mathrm{N} \\
\mathrm{C}\end{array}$ & $\begin{array}{l}\mathrm{NCa} \\
\mathrm{Ca}\end{array}$ & $\begin{array}{l}0,87 \\
0,15\end{array}$ & $\begin{array}{l}20444 \\
20493\end{array}$ \\
\hline Araceae & $\begin{array}{l}\text { Philodendron acutatum } \\
\text { Schott } \\
\text { Dieffenbachia } \mathrm{sp} .\end{array}$ & $\begin{array}{l}\text { imbé } \\
\text { comigo-ninguém-pode }\end{array}$ & $\begin{array}{l}\mathrm{AR} \\
\mathrm{OR}, \mathrm{RL}\end{array}$ & $\begin{array}{l}1 \\
9\end{array}$ & $\begin{array}{l}\mathrm{N} \\
\mathrm{NO}\end{array}$ & $\begin{array}{l}\mathrm{NCa} \\
\mathrm{Ca}\end{array}$ & $\begin{array}{l}0,03 \\
0,23\end{array}$ & $\begin{array}{l}20445 \\
22052\end{array}$ \\
\hline Arecaceae & $\begin{array}{l}\text { Allagoptera sp. } \\
\text { Cocos nucifera } \mathrm{L} . \\
\text { Syagrus sp. } \\
\text { Syagrus coronata } \\
\text { (Mart.) Becc. } \\
\text { Dypsis lutescens (H. } \\
\text { Wendl.) Beentje \& J. } \\
\text { Dransf. } \\
\text { Bactris sp. }\end{array}$ & $\begin{array}{l}\text { coco cachindó } \\
\text { coqueiro } \\
\text { coco de caatinga } \\
\text { ouricuri, licuri } \\
\text { palmeira } \\
\text { tucum }\end{array}$ & $\begin{array}{l}\text { AL } \\
\text { AL } \\
\text { AL } \\
\text { AR, AL, MD } \\
\text { OR, RL } \\
\text { AL }\end{array}$ & $\begin{array}{l}2 \\
20 \\
7 \\
54 \\
17 \\
1\end{array}$ & $\begin{array}{l}\mathrm{N} \\
\mathrm{N} \\
\mathrm{N} \\
\mathrm{N} \\
\mathrm{NO} \\
\mathrm{Nat}\end{array}$ & $\begin{array}{l}\mathrm{NCa} \\
\mathrm{Ca} \\
\mathrm{NCa} \\
\mathrm{NCa} \\
\mathrm{Ca} \\
\mathrm{NCa}\end{array}$ & $\begin{array}{l}0,05 \\
0,51 \\
0,18 \\
1,38 \\
0,44 \\
0,03\end{array}$ & $\begin{array}{l}21188 \\
22048 \\
22068 \\
20634 \\
22994 \\
20661\end{array}$ \\
\hline Boraginaceae & Heliotropium indicum $\mathrm{L}$. & crista-de-galo & MD & 4 & $\mathrm{~N}$ & $\mathrm{NCa}$ & 0,10 & 20640 \\
\hline Bromeliaceae & $\begin{array}{l}\text { Ananas sativus Schult. \& } \\
\text { Schult. F }\end{array}$ & abacaxi & $\mathrm{AL}$ & 4 & $\mathrm{~N}$ & $\mathrm{Ca}$ & 0,10 & 22066 \\
\hline Cactaceae & $\begin{array}{l}\text { Melocactus } \\
\text { zehntneri (Britton \& } \\
\text { Rose) Luetzelb. }\end{array}$ & cabeça-de-frade & OR, RL & 2 & $\mathrm{~N}$ & $\mathrm{NCa}$ & 0,05 & 22991 \\
\hline Cannabaceae & Celtis sp. & camarão & RL & 4 & $\mathrm{~N}$ & $\mathrm{NCa}$ & 0,10 & 23006 \\
\hline $\begin{array}{l}\text { Caricaceae } \\
\text { Combretaceae }\end{array}$ & $\begin{array}{l}\text { Carica papaya } \mathrm{L} . \\
\text { Terminalia catappa } \mathrm{L} .\end{array}$ & $\begin{array}{l}\text { mamão } \\
\text { amêndoa }\end{array}$ & $\begin{array}{l}\mathrm{AL} \\
\mathrm{MD}\end{array}$ & $\begin{array}{l}4 \\
1\end{array}$ & $\begin{array}{l}\text { Nat } \\
\text { Nat }\end{array}$ & $\begin{array}{l}\mathrm{Ca} \\
\mathrm{NCa}\end{array}$ & $\begin{array}{l}0,10 \\
0,03\end{array}$ & $\begin{array}{l}20654 \\
21174\end{array}$ \\
\hline Convolvulaceae & $\begin{array}{l}\text { Ipomoea batatas (L.) } \\
\text { Lam. }\end{array}$ & batata-doce & $\mathrm{AL}$ & 14 & Nat & $\mathrm{Ca}$ & 0,36 & 21165 \\
\hline Costaceae & $\begin{array}{l}\text { Costus spicatus (Jacq.) } \\
\text { Sw. }\end{array}$ & cana-do-brejo & MD & 4 & NO & $\mathrm{NCa}$ & 0,15 & 21185 \\
\hline Cucurbitaceae & $\begin{array}{l}\text { Cucurbita moschata } \\
\text { Duchesne } \\
\text { Citrullus lanatus } \\
\text { (Thunb.) Matsum. \& } \\
\text { Nakai } \\
\text { Luffa operculata }(\mathrm{L} .) \\
\text { Cogn. }\end{array}$ & $\begin{array}{l}\text { abóbora } \\
\text { melancia } \\
\text { pulga-de-burro/buxo }\end{array}$ & $\begin{array}{l}\mathrm{AL} \\
\mathrm{AL} \\
\mathrm{O}\end{array}$ & 10 & $\begin{array}{l}\mathrm{C} \\
\mathrm{N}\end{array}$ & $\begin{array}{l}\mathrm{Ca} \\
\mathrm{Ca} \\
\mathrm{NCa}\end{array}$ & $\begin{array}{l}0,13 \\
0,26 \\
0,18\end{array}$ & $\begin{array}{l}20659 \\
21194 \\
22053\end{array}$ \\
\hline Dioscoreaceae & Dioscorea sp. & inhame & $\mathrm{AL}$ & 3 & $\mathrm{~N}$ & $\mathrm{Ca}$ & 0,08 & 23013 \\
\hline
\end{tabular}




\begin{tabular}{|c|c|c|c|c|c|c|c|c|}
\hline Euphorbiaceae & $\begin{array}{l}\text { Cnidoscolus urens (L.) } \\
\text { Arthur } \\
\text { Manihot esculenta } \\
\text { Crantz } \\
\text { Jatropha curcas L. } \\
\text { Croton heliotropiifolius } \\
\text { Kunth }\end{array}$ & $\begin{array}{l}\text { cansanção } \\
\text { macaxeira, mandioca } \\
\text { pinhão roxo } \\
\text { velane }\end{array}$ & $\begin{array}{l}\text { MD } \\
\text { AL } \\
\text { RL } \\
\text { MD }\end{array}$ & $\begin{array}{l}3 \\
35 \\
7 \\
1\end{array}$ & $\begin{array}{l}\mathrm{N} \\
\mathrm{N} \\
\mathrm{Nat} \\
\mathrm{N}\end{array}$ & $\begin{array}{l}\mathrm{NCa} \\
\mathrm{Ca} \\
\mathrm{Ca} \\
\mathrm{NCa}\end{array}$ & $\begin{array}{l}0,89 \\
0,54 \\
0,18\end{array}$ & $\begin{array}{l}22071 \\
20487 \\
20443\end{array}$ \\
\hline Fabaceae & $\begin{array}{l}\text { Vigna unguiculata (L.) } \\
\text { Walp. }\end{array}$ & feijão & $\mathrm{AL}$ & 21 & Nat & $\mathrm{Ca}$ & 0,54 & 21154 \\
\hline Heliconiaceae & $\begin{array}{l}\text { Heliconia psittacorum L. } \\
\text { f. }\end{array}$ & alevante & MD & 2 & $\mathrm{~N}$ & $\mathrm{NCa}$ & 0,08 & 20645 \\
\hline Humiriaceae & $\begin{array}{l}\text { Sacoglottis guianensis } \\
\text { Benth. }\end{array}$ & oiti & $\mathrm{AL}$ & 3 & $\mathrm{~N}$ & $\mathrm{NCa}$ & 0,08 & 21172 \\
\hline Lamiaceae & $\begin{array}{l}\text { Mentha sp. } \\
\text { Eplingiella fruticosa } \\
\text { (Salzm. ex Benth.) } \\
\text { Harley \& J.F.B. Pastore } \\
\text { Plectranthus amboinicus } \\
\text { (Lour.) Spreng. } \\
\text { Ocimum basilicum L. } \\
\text { Mesosphaerum } \\
\text { pectinatum (L.) Kuntze }\end{array}$ & $\begin{array}{l}\text { hortelã miúdo, pequeno } \\
\text { alecrim } \\
\text { hortelã grande, sigulera } \\
\text { manjericão } \\
\text { sambacaetá }\end{array}$ & $\begin{array}{l}\text { MD } \\
\text { MD } \\
\text { MD, AL } \\
\text { AL, MD } \\
\text { MD }\end{array}$ & $\begin{array}{l}14 \\
10 \\
11\end{array}$ & $\begin{array}{l}\text { Nat } \\
\mathrm{N} \\
\mathrm{NO} \\
\mathrm{NO} \\
\mathrm{N}\end{array}$ & $\begin{array}{l}\mathrm{Ca} \\
\mathrm{NCa} \\
\mathrm{Ca} \\
\mathrm{Ca} \\
\mathrm{NCa}\end{array}$ & $\begin{array}{l}0,21 \\
0,03 \\
0,46 \\
0,28 \\
0,38\end{array}$ & $\begin{array}{l}23001 \\
20438 \\
23008 \\
21158 \\
21199\end{array}$ \\
\hline Lauraceae & Cassytha filiformis $\mathrm{L}$. & cipó de chumbo & MD & 2 & $\mathrm{~N}$ & $\mathrm{NCa}$ & 0,05 & 20489 \\
\hline Leguminosae & $\begin{array}{l}\text { Chamaecrista hispidula } \\
\text { (Vahl) H.S. Irwin \& } \\
\text { Barneby } \\
\text { Senna obtusifolia (L.) } \\
\text { H.S. Irwin \& Barneby } \\
\text { Hymenaea } \text { sp. } \\
\text { Caesalpinia ferrea Mart. } \\
\text { Desmodium barbatum } \\
\text { (L.) Benth. } \\
\text { Tamarindus indica } \text { L. } \\
\text { Inga } \text { sp. }\end{array}$ & $\begin{array}{l}\text { carobinha } \\
\text { fedegoso } \\
\text { jatobá } \\
\text { pau-ferro } \\
\text { quebra-pedra rasteiro } \\
\text { tamarindo } \\
\text { babatenã }\end{array}$ & $\begin{array}{l}\text { MD } \\
\mathrm{MD}, \mathrm{RL} \\
\mathrm{MD} \\
\mathrm{MD} \\
\mathrm{MD} \\
\mathrm{AL} \\
\mathrm{MD}, \mathrm{O}\end{array}$ & $\begin{array}{l}11 \\
3 \\
3 \\
1 \\
2 \\
20\end{array}$ & $\begin{array}{l}\mathrm{N} \\
\mathrm{N} \\
\mathrm{N} \\
\mathrm{N} \\
\mathrm{N} \\
\mathrm{C} \\
\mathrm{N}\end{array}$ & $\begin{array}{l}\mathrm{NCa} \\
\mathrm{NCa} \\
\mathrm{NCa} \\
\mathrm{NCa} \\
\mathrm{NCa} \\
\mathrm{Ca} \\
\mathrm{NCa}\end{array}$ & $\begin{array}{l}0,13 \\
0,28 \\
0,08 \\
0,08 \\
0,03 \\
0,05 \\
0,62\end{array}$ & $\begin{array}{l}20637 \\
20647 \\
22087 \\
21200 \\
21157 \\
21197 \\
22075\end{array}$ \\
\hline Leguminosae & $\begin{array}{l}\text { Inga } \text { cf fagifolia G. Don } \\
\text { Periandra mediterranea } \\
\text { (Vell.) Taub. } \\
\text { Cajanus cajan (L.) Huth } \\
\text { Bowdichia cf virgilioides } \\
\text { Kunth }\end{array}$ & $\begin{array}{l}\text { ingá } \\
\text { aconsu } \\
\text { feijão } \\
\text { sucupira }\end{array}$ & $\begin{array}{l}\text { AL } \\
\text { MD } \\
\text { AL } \\
\text { MD }\end{array}$ & $\begin{array}{l}1 \\
1 \\
21 \\
2\end{array}$ & $\begin{array}{l}\mathrm{N} \\
\mathrm{N} \\
\mathrm{C} \\
\mathrm{N}\end{array}$ & $\begin{array}{l}\mathrm{NCa} \\
\mathrm{NCa} \\
\mathrm{Ca} \\
\mathrm{NCa}\end{array}$ & $\begin{array}{l}0,03 \\
0,03 \\
0,54 \\
0,05\end{array}$ & $\begin{array}{l}22992 \\
21181 \\
21168 \\
23010\end{array}$ \\
\hline Loranthaceae & $\begin{array}{l}\text { Psittacanthus dichrous } \\
\text { (Mart.) Mart. }\end{array}$ & encherco, enxerto & MD & 1 & $\mathrm{~N}$ & $\mathrm{NCa}$ & 0,03 & 21170 \\
\hline Malpighiaceae & $\begin{array}{l}\text { Malpighia emarginata } \\
\text { DC. } \\
\text { Byrsonima verbascifolia } \\
\text { (L.) DC. }\end{array}$ & $\begin{array}{l}\text { acerola } \\
\text { murici, murici preto }\end{array}$ & $\begin{array}{l}\mathrm{AL} \\
\mathrm{AL}\end{array}$ & $\begin{array}{l}5 \\
25\end{array}$ & $\begin{array}{l}\mathrm{NO} \\
\mathrm{N}\end{array}$ & $\begin{array}{l}\mathrm{Ca} \\
\mathrm{NCa}\end{array}$ & $\begin{array}{l}0,13 \\
0,72\end{array}$ & $\begin{array}{l}20657 \\
20492\end{array}$ \\
\hline Malvaceae & Sida glaziovii K. Schum. & malva-branca & $\mathrm{MD}, \mathrm{RL}$ & 23 & $\mathrm{~N}$ & $\mathrm{Ca}$ & 0,72 & 20646 \\
\hline Melastomataceae & $\begin{array}{l}\text { Mouriri guianensis } \\
\text { Aubl. } \\
\text { Mouriri pusa Gardner ex } \\
\text { Gardner }\end{array}$ & $\begin{array}{l}\text { curiri, cruiri } \\
\text { manipuçá, mão de puçá }\end{array}$ & $\begin{array}{l}\text { MD } \\
\text { AL }\end{array}$ & $\begin{array}{l}1 \\
2\end{array}$ & $\begin{array}{l}\mathrm{N} \\
\mathrm{N}\end{array}$ & $\begin{array}{l}\mathrm{NCa} \\
\mathrm{NCa}\end{array}$ & $\begin{array}{l}0,03 \\
0,05\end{array}$ & $\begin{array}{l}21177 \\
22077\end{array}$ \\
\hline Meliaceae & $\begin{array}{l}\text { Azadirachta indica A. } \\
\text { Juss. }\end{array}$ & nim & $\mathrm{O}$ & 3 & NO & $\mathrm{Ca}$ & 0,08 & 21163 \\
\hline Moraceae & $\begin{array}{l}\text { Artocarpus integrifolia } \\
\text { L. f. }\end{array}$ & jaca & AL & 6 & NO & $\mathrm{Ca}$ & 0,15 & 21182 \\
\hline Musaceae & Musa paradisiaca $\mathrm{L}$. & banana & $\mathrm{AL}$ & 24 & $\mathrm{~N}$ & $\mathrm{Ca}$ & 0,62 & 21186 \\
\hline Myrtaceae & $\begin{array}{l}\text { Psidium sp. } \\
\text { Neomitranthes cf obtusa } \\
\text { Sobral \& Zambom }\end{array}$ & $\begin{array}{l}\text { araçá } \\
\text { cambucá }\end{array}$ & $\begin{array}{l}\mathrm{AL} \\
\mathrm{AL}\end{array}$ & $\begin{array}{l}6 \\
17\end{array}$ & $\begin{array}{l}\mathrm{N} \\
\mathrm{N}\end{array}$ & $\begin{array}{l}\mathrm{NCa} \\
\mathrm{NCa}\end{array}$ & $\begin{array}{l}0,15 \\
0,44\end{array}$ & $\begin{array}{l}20662 \\
22990\end{array}$ \\
\hline
\end{tabular}




\begin{tabular}{|c|c|c|c|c|c|c|c|c|}
\hline & $\begin{array}{l}\text { Myrcia } \\
\text { polyantha (Kunth) DC. } \\
\text { Psidium guajava L. } \\
\text { Eugenia punicifolia } \\
\text { (Kunth) DC. } \\
\text { Eugenia uniflora } \mathrm{L} \text {. }\end{array}$ & $\begin{array}{l}\text { cambuí } \\
\text { goiaba } \\
\text { murta } \\
\text { pitanga }\end{array}$ & $\begin{array}{l}\mathrm{AL} \\
\mathrm{AL} \\
\mathrm{AL} \\
\mathrm{AL}, \mathrm{MD}\end{array}$ & $\begin{array}{l}16 \\
5 \\
5 \\
4\end{array}$ & $\begin{array}{l}\mathrm{N} \\
\mathrm{Nat} \\
\mathrm{N} \\
\mathrm{N}\end{array}$ & $\begin{array}{l}\mathrm{NCa} \\
\mathrm{NCa} \\
\mathrm{NCa} \\
\mathrm{Ca}\end{array}$ & $\begin{array}{l}0,41 \\
0,13 \\
0,13 \\
0,13\end{array}$ & $\begin{array}{l}22989 \\
22998 \\
22988 \\
21196\end{array}$ \\
\hline Orchidaceae & $\begin{array}{l}\text { Vanilla palmarum } \\
\text { (Salzm. ex Lindl.) Lindl. }\end{array}$ & banana de macaco & MD & 1 & $\mathrm{~N}$ & $\mathrm{NCa}$ & 0,03 & 21184 \\
\hline Passifloraceae & Passiflora edulis Sims & maracujá & AL, MD & 11 & $\mathrm{~N}$ & $\mathrm{Ca}$ & 0,28 & 20483 \\
\hline Phyllanthaceae & Phyllanthus niruri L. & quebra-pedra & MD & 6 & $\mathrm{~N}$ & $\mathrm{NCa}$ & 0,15 & 20641 \\
\hline Phytolaccaceae & Petiveria alliacea $\mathrm{L}$. & tipi & MD, OR, RL & 4 & Nat & $\mathrm{Ca}$ & 0,10 & 22047 \\
\hline Plantaginaceae & Scoparia dulcis $\mathrm{L}$. & vassorinha & RL, MD & 14 & $\mathrm{~N}$ & $\mathrm{NCa}$ & 0,36 & 20485 \\
\hline Rubiaceae & $\begin{array}{l}\text { Cymbopogon sp. } \\
\text { Saccharum } \\
\text { officinarum } \mathrm{L} \text {. } \\
\text { Zea mays } \mathrm{L} \text {. } \\
\text { Genipa americana } \mathrm{L} \text {. } \\
\text { Rudgea sp. }\end{array}$ & $\begin{array}{l}\text { capim-santo } \\
\text { cana } \\
\text { milho } \\
\text { jenipapo } \\
\text { mamelada }\end{array}$ & $\begin{array}{l}\mathrm{MD} \\
\mathrm{AL} \\
\mathrm{AL} \\
\mathrm{AL} \\
\mathrm{AL}\end{array}$ & $\begin{array}{l}23 \\
2 \\
24 \\
7 \\
4\end{array}$ & $\begin{array}{l}\mathrm{Nat} \\
\mathrm{C} \\
\mathrm{C} \\
\mathrm{N} \\
\mathrm{N}\end{array}$ & $\begin{array}{l}\mathrm{Ca} \\
\mathrm{Ca} \\
\mathrm{Ca} \\
\mathrm{NCa} \\
\mathrm{NCa}\end{array}$ & $\begin{array}{l}0,77 \\
0,05 \\
0,62 \\
0,18 \\
0,10\end{array}$ & \begin{tabular}{|l|}
22995 \\
22067 \\
20644 \\
21175 \\
23007
\end{tabular} \\
\hline Rutaceae & $\begin{array}{l}\text { Citrus aurantium } \mathrm{L} \text {. } \\
\text { Citrus sp. }\end{array}$ & $\begin{array}{l}\text { laranja } \\
\text { limão }\end{array}$ & $\begin{array}{l}\mathrm{AL} \\
\mathrm{AL}, \mathrm{MD}\end{array}$ & 14 & $\begin{array}{l}\text { Nat } \\
\text { Nat }\end{array}$ & $\begin{array}{l}\mathrm{Ca} \\
\mathrm{Ca}\end{array}$ & $\begin{array}{l}0,36 \\
0,15\end{array}$ & $\begin{array}{l}20655 \\
22051\end{array}$ \\
\hline Sapotaceae & $\begin{array}{l}\text { Manilkara salzmannii } \\
\text { (A. DC.) H.J. Lam }\end{array}$ & maçaranduba & AL & 7 & $\mathrm{~N}$ & $\mathrm{NCa}$ & 0,18 & 21189 \\
\hline Simaroubaceae & Simarouba sp. & pau pra tudo & MD & 1 & $\mathrm{~N}$ & $\mathrm{NCa}$ & 0,03 & 23085 \\
\hline Solanaceae & $\begin{array}{l}\text { Solanum paniculatum } \mathrm{L} \text {. } \\
\text { Capsicum frutescens } \mathrm{L} . \\
\text { Solanum lycocarpum A. } \\
\text { St.-Hil. }\end{array}$ & $\begin{array}{l}\text { jurubeba } \\
\text { pimenta } \\
\text { tomate }\end{array}$ & $\begin{array}{l}\text { MD } \\
\text { RL, AL } \\
\text { AL }\end{array}$ & $\begin{array}{l}10 \\
1 \\
6\end{array}$ & $\begin{array}{l}\mathrm{N} \\
\mathrm{Nat} \\
\mathrm{N}\end{array}$ & $\begin{array}{l}\mathrm{NCa} \\
\mathrm{Ca} \\
\mathrm{Ca}\end{array}$ & $\begin{array}{l}0,36 \\
0,03 \\
0,15\end{array}$ & $\begin{array}{l}20441 \\
20656 \\
21195\end{array}$ \\
\hline Typhaceae & Typha sp. & tabua & $\mathrm{AR}, \mathrm{MD}$ & 6 & $\mathrm{~N}$ & $\mathrm{NCa}$ & 0,15 & 22073 \\
\hline Verbenaceae & $\begin{array}{l}\text { Lippia alba (Mill.) N.E. } \\
\text { Br. ex Britton \& P. } \\
\text { Wilson }\end{array}$ & cidreira, macineira & MD & 26 & $\mathrm{~N}$ & $\mathrm{Ca}, \mathrm{NCa}$ & 0,87 & 20495 \\
\hline
\end{tabular}

FONTE: ELABORAÇÃO PRÓPRIA

NOTA: $\mathrm{O}=$ outros; $\mathrm{MD}=$ medicinal; $\mathrm{AL}=$ alimentícia; $\mathrm{OR}=$ ornamental; $\mathrm{AR}=$ artesanal; $\mathrm{RL}=$ místico-religioso; $\mathrm{NC}$ = número de citações; Ori = origem em relação ao Brasil; $\mathrm{NO}=$ não ocorre no Brasil; $\mathrm{N}$ = nativa; $\mathrm{Nat}$ = naturalizada; $\mathrm{C}=$ cultivada; $\mathrm{Oc}=$ ocorrência no assentamento de acordo com os moradores $; \mathrm{Ca}=$ cultivada pelos assentados e/ou $\mathrm{NCa}$ = presente "naturalmente" no assentamento, sem cultivo pelos assentados; VU = valor de uso; ASE = material botânico testemunho depositado no Herbário ASE.

Segundo informações obtidas com os assentados, das 90 espécies identificadas que estão presentes no assentamento, pouco mais da metade $(55,6 \%)$ ocorrem na área sem que os assentados as cultivem, entre as quais se encontram duas das três espécies com maiores valores de uso: o ouricurizeiro (S. coronata) e a mangabeira (H. speciosa). Por sua vez, 37 espécies $(41,1 \%)$ só ocorrem na área por serem cultivadas pelos assentados, entre elas, a segunda espécie com maior valor de uso: macaxeira/mandioca ( $M$. esculenta). Apenas três espécies $(3,3 \%)$ são cultivadas pelos assentados ainda que ocorram "naturalmente" na área sem necessidade de cultivo, a saber: cidreira/macineira (Lippia alba), cajueiro (Anacardium occidentale) e mangueira (Mangifera indica). As duas primeiras, 
espécies nativas do Brasil, são cultivadas ainda que ocorram abundantemente na área, devido às propriedades medicinais e apreciação do fruto na alimentação humana, respectivamente. Já a última, espécie cultivada, já existia na área antes da posse pelos assentados que, além de manterem os exemplares existentes, plantaram mais para apreciação do fruto na alimentação, bem como sua venda sazonal.

As categorias de uso com maior número de citações para as espécies foram: Medicinal (45) e Alimentícia (44), em seguida, Místico-religiosa (10), Ornamental (5), Outros (4) e Artesanato (3). São comuns os maiores números de citação para espécies nas categorias Alimentícia e Medicinal, visto que estas influenciam na sobrevivência das populações que lidam diretamente com a exploração dos recursos naturais, como é o caso dos assentamentos agroextrativistas. Estudos em restinga encontraram distribuições semelhantes nas categorias de uso, com maior concentração das espécies nas categorias Alimentícia e Medicinal (MIRANDA; HANAZAKI, 2008; GANDOLFO; HANAZAKI, 2011), bem como estudos em outras regiões fitogeográficas do Brasil (ALBUQUERQUE et al., 2009; CARTAXO; SOUZA; ALBUQUERQUE, 2010; PASA; SOARES; GUARIM NETO, 2005).

Quanto à distribuição das categorias de uso nas três zonas de recurso utilizadas pelos assentados (Figura 1), pode-se afirmar que a coleta das espécies alimentícias é bem distribuída entre o quintal (32), o lote (23) e a mata nativa (21), evidenciando que a alimentação é prioridade para a comunidade, sendo ativamente presente em qualquer ambiente onde exerce suas atividades diárias. Por sua vez, as espécies enquadradas como medicinais ocorrem em grande quantidade nos quintais (33) e na mata (24), porém, são quase inexistentes nos lotes (4), enquanto as místico-religiosas e ornamentais não ocorrem nos lotes, apenas nos quintais (8 e 5) e na mata (4 e 1), com maior presença nos quintais, isto é, cultivadas pelos moradores.

Os pesquisadores Oliveira, Santos e Gomes (2014) estudaram detalhadamente a zona de recurso "quintal" em 89\% das residências do PAE São Sebastião. Nesse estudo, detectaram que as 10 espécies (com DNS $\geq 3 \mathrm{~cm}$ ) de maior ocorrência e abundância nos quintais do assentamento são da categoria Alimentícia, das quais três se destacaram devido à sua importância socioeconômica, a saber: coqueiros (C. nucifera) com 127 indivíduos catalogados em 24 quintais; touceiras de bananeiras e/ou indivíduos isolados (M. paradisiaca), que ocorreram 129 vezes em 20 quintais; e o ouricurizeiros $(S$. coronata), com 106 ocorrências em 19 quintais.

Para Pulido et al. (2008), espera-se que a ação humana em relação ao manejo e à seleção de espécies seja afetada por elementos que fazem parte dos costumes locais, pois estabelecer um quintal, em diversas culturas, é questão de status social, desse modo, as espécies estabelecidas nos quintais 
refletem o nível socioeconômico da família. Assim, a distribuição de espécies alimentícias por parte dos moradores em todas as áreas de coleta, bem como o alto número de plantas medicinais cultivadas nos quintais (OLIVEIRA; SANTOS; GOMES, 2014), coincide com a situação socioeconômica do PAE São Sebastião: de agricultura familiar de subsistência, dentro dos moldes de um assentamento de reforma agrária com tempo recente de criação, e de carência de assistência médica.

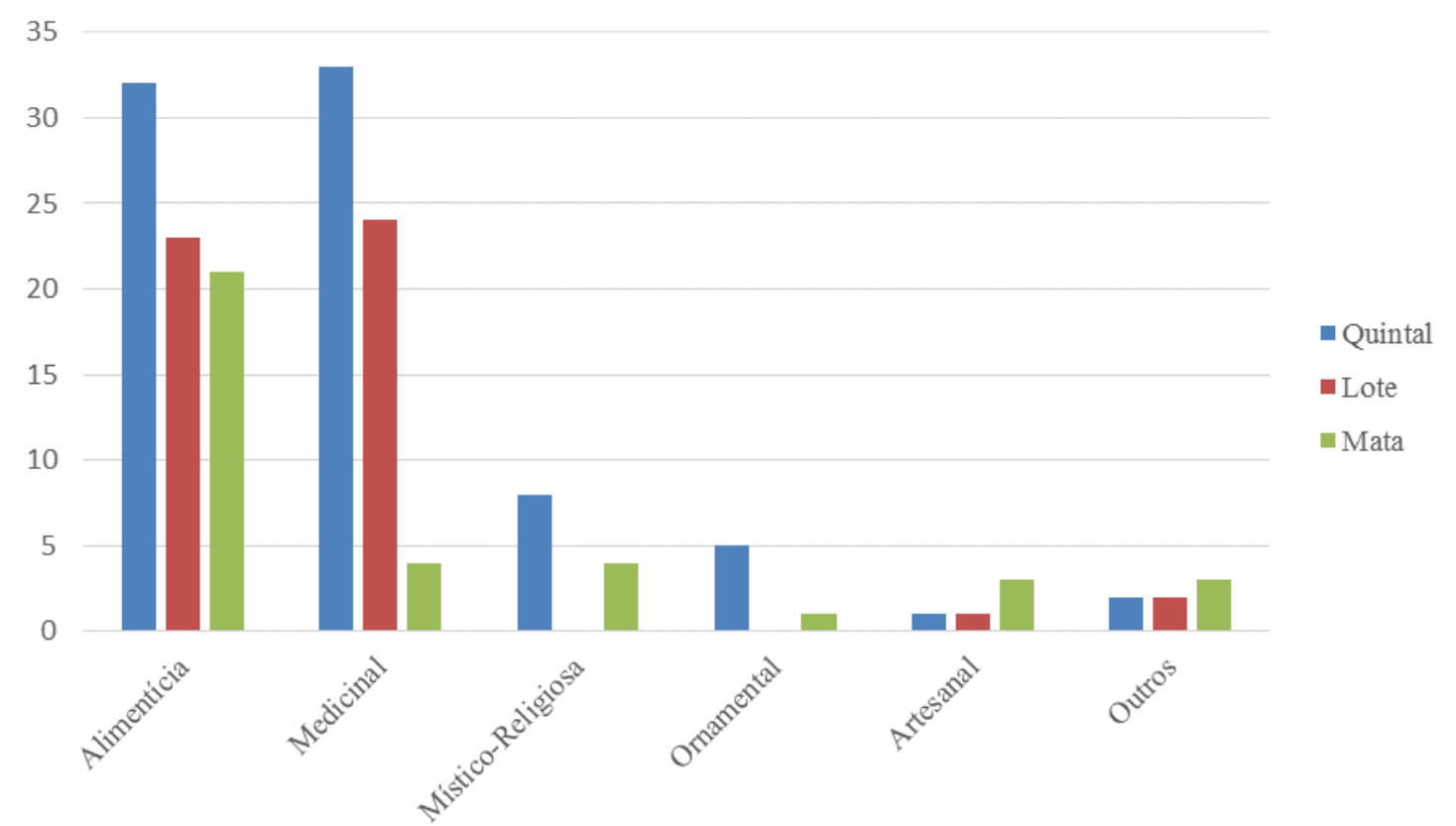

FIGURA 1 - DISTRIBUIÇÃO DAS ESPÉCIES NOS QUINTAIS, LOTES E MATA NATIVA LOCAL, DE ACORDO COM AS CATEGORIAS DE USO EM QUE SÃO ENQUADRADAS

FONTE: PESQUISA (2011).

Das 10 espécies com maior valor de uso, $60 \%$ se enquadram na categoria de uso Medicinal e 50\% na categoria Alimentícia, corroborando com o maior número de espécies úteis citadas para essas categorias. Como o ouricurizeiro (S. coronata), a macaxeira/mandioca (M. esculenta) e a mangabeira (H. speciosa) são espécies essenciais à geração de renda para as famílias, o valor de uso para essas espécies foram os mais elevados, respectivamente 1,38, 0,89 e 0,87.

Um estudo realizado no estado de Pernambuco mostrou que o ouricurizeiro ( $S$. coronata) é uma espécie versátil na localidade estudada, pois a espécie foi enquadrada em todas essas categorias de uso, distribuído em 32 usos diferentes (Rufino et al. 2008). Já no PAE São Sebastião as 54 citações para o ouricurizeiro se enquadraram apenas em três categorias: Artesanato (39), Alimentícia (12) e Medicinal (3), com apenas quatro usos distintos: artesanato de chapéu (39), artesanato de vassoura (1), alimento humano (12) e colírio para os olhos (2). 
A mangabeira (H. speciosa) tem sido explorada com maior intensidade pelas populações extrativistas de áreas de restinga do estado de Sergipe, notadamente, após o declínio de outros tipos de recursos extrativistas, como os caranguejos nos manguezais. Como consequência, investem na conservação desse recurso e ao mesmo tempo intensificam a pressão de uso sobre ele (MOTA; SANTOS, 2008). No PAE São Sebastião essa realidade é bastante evidenciada, na medida em que os moradores relataram que "limpam" os pés de mangabeiras de outras espécies vegetais que possam prejudicá-los, o que configura uma ação no sentido de zelar pelo recurso.

\section{Análise por categorias de uso}

\section{a. Alimentícias}

Ao todo foram identificadas 44 espécies alimentícias, distribuídas em 34 famílias e 40 gêneros botânicos, das quais 24 (54,5\%) são nativas do Brasil, oito $(18,2 \%)$ são naturalizadas, sete $(15,9 \%)$ são cultivadas e apenas cinco $(11,3 \%)$ não ocorrem no país. As famílias mais representativas foram Myrtaceae (6) e Arecaceae (5), e as espécies mais citadas foram: ouricuri (54, S. coronata), macaxeira/mandioca (35, M. esculenta), mangaba (31, H. speciosa), manga $(27$, M. indica) e murici (25, Byrsonima verbascifolia).

Entre as espécies alimentícias, 25 (56,8\%) só ocorrem no assentamento, pois são cultivadas pelos assentados, enquanto $17(38,6 \%)$ não são cultivadas por ocorrerem "naturalmente" na área, bem como duas $(4,6 \%)$ são cultivadas ainda que ocorram "naturalmente" na área. O maior número de espécies alimentícias cultivadas pelos assentados reforça que a base alimentar das famílias é predominantemente dependente da agricultura familiar local, visto que a renda obtida com o extrativismo é sazonal, conforme comentário como o que segue: "No tempo da mangaba é que fica bom... Depois a gente fica com muito pouco, só come o que dá na roça" (M5, 42 anos). Assim, as famílias do assentamento continuam a depender da sazonalidade tanto do extrativismo quanto da colheita de um estreito rol de culturas.

Entre as espécies alimentícias que ocorrem no assentamento sem que seja necessário o cultivo por parte dos moradores, duas obtiveram elevado número de citações: o cambuí (17, Myrcia sp.) e o cambucá (16, Neomitranthes cf obtusa), ambas espécies nativas muito apreciadas pelos moradores enquanto estão realizando outras atividades na mata, conforme ilustra o comentário: "Eles dá na mesma época mais ou menos... A gente vai pra caatinga e volta com a barriga cheia deles!” (M5, 42 anos). Contudo, apesar de apreciadas, por não estarem diretamente relacionadas à segurança alimentar e à subsistência familiar, essas espécies de ocorrência "natural" na área não são cultivadas pelos assentados, diferente dos cajueiros e das mangueiras. 
Com relação às espécies alimentícias citadas por homens ou mulheres, das 10 espécies alimentícias com maior número de citações por homens e mulheres, sete são comuns entre eles, a saber: manga (M. indica), mangaba (H. speciosa), mandioca/macaxeira (M. esculenta), banana (M. paradisiaca), coco (C. nucifera), milho (Z. mays) e cambucá ( $N$. cf obtusa), inferindo-se que essas espécies são as de maior importância para a manutenção da alimentação familiar e apreciação local.

No entanto, algumas espécies foram citadas dentro da categoria Alimentícias apenas por homens $(\mathrm{H})$ ou mulheres $(\mathrm{M})$. Foram elas: coco de caatinga $(7 \mathrm{H}$, Syagrus sp.), goiaba $(5 \mathrm{H}$, Psidium guajava.), manipuçá (2H, Mouriri pusa), siriguela (2H, Spondias purpurea), tucum (1H, Bactris sp.), manjericão (2M, Ocimum basilicum), hortelã grande/sigulera (2M, Plectranthus amboinicus), oiti (1M, Sacoglottis guianensis) e pitanga (1M, Eugenia uniflora). Isso pode refletir a importância que essas espécies têm para os diferentes gêneros, destacando o cotidiano diferenciado que coloca determinadas espécies em maior contato com um ou outro gênero.

Por exemplo, o coco de caatinga (Syagrus sp.) pertence a uma espécie de palmeira conhecida popularmente como piaçava/piaçaba, que ocorre em áreas de areias brancas de difícil acesso, onde os homens circulam com maior frequência (exceto quando é época da coleta das mangabas), por isso a recordação desse recurso por parte dos homens. Já no caso do manjericão (O. basilicum) e da hortelã-grande/sigulera (P. amboinicus), citados apenas por mulheres, evidencia-se o cotidiano doméstico na responsabilidade de preparar os alimentos, visto que ambos foram citados na categoria Alimentícia com a posterior ressalva por parte das mulheres de que eram usados como condimentos, bem como cultivados por elas nos quintais de acordo com Oliveira, Santos e Gomes (2014).

\section{b. Medicinais}

Foram identificadas um total de 45 espécies utilizadas para fins terapêuticos, distribuídas em 29 famílias, das quais as mais representativas foram Leguminosae (8), Lamiaceae (4), Amaranthaceae (3) e Apocynaceae (3); e 45 gêneros botânicos. Destas, 32 (71,1\%) são nativas do Brasil, nove (20\%) são naturalizadas, três $(6,7 \%)$ não ocorrem no país e uma $(2,2 \%)$ é cultivada. Diferentemente da categoria alimentícia, os assentados cultivam menos espécies medicinais $(31,68,9 \%)$ - doze espécies $(26,7 \%)$ são cultivadas e apenas duas $(4,4 \%)$ são cultivadas ainda que ocorram de maneira natural no assentamento, a saber: caju (A. occidentale) e cidreira/macineira ( $L$. alba), sendo que a primeira é cultivada predominantemente por enquadrar-se na categoria Alimentícia.

Um trabalho com plantas medicinais em área de restinga encontrou um menor número de espécies medicinais, em uma comunidade em Camaçari-BA, cuja população estudada mencionou o 
conhecimento de 23 espécies (SOUZA; ARAÚJO; SANTOS, 2007); por outro lado, também foi encontrado um maior número de espécies em uma comunidade no litoral do Rio de Janeiro, que citou 91 espécies para essa categoria (BOSCOLO; VALLE, 2008), o que indica que pode não estar havendo um padrão relacionado ao ecossistema.

As espécies com maior número de citações para a categoria foram: cidreira/macineira (26, L. alba), malva-branca (23, Sida glaziovii), campim-santo (23, Cymbopogon sp.), hortelã-grande/sigulera (16, P. amboinicus), babatenã (13, Inga sp.), mastruz (11, Chenopodium ambrosioides), sambacaetá (11, Hyptis pectinata) e jurubeba (10, Solanum paniculatum).

Dezessete espécies $(37,8 \%)$ foram indicadas exclusivamente por homens e seis por mulheres $(13,4 \%)$ dentro dessa categoria, apesar de estas não estarem relacionadas a indicações de tratamentos para apenas um dos gêneros. As demais espécies, um pouco menos da metade $(48,8 \%)$, foram indicadas por ambos os gêneros. A maioria das espécies $(31,69 \%)$ obteve apenas uma ou duas indicações de uso dentro da categoria medicinais, o que demonstra que as espécies conhecidas possuem pouca versatilidade atribuída pelos moradores da região. Em contraste, o estudo desenvolvido por Boscolo e Valle (2008), também em uma região de restinga do Rio de Janeiro, encontrou indicações de uso terapêutico de espécies que foram citadas pelos assentados, mas não na categoria Medicinal, como a cana-de-açúcar (Saccharum officinarum), a banana (M. paradisiaca) e o milho (Z. may) com respectivamente 13, 10 e quatro indicações de uso terapêutico diferentes.

A parte mais usada das plantas foram as folhas (com 25 citações), e o meio mais comum de administração dos medicamentos foi o chá (entenda-se por chá o líquido obtido a partir do cozimento da respectiva parte da planta em água). O uso das folhas como parte funcional do medicamento na planta e do chá como meio de administração também coincidem com outras publicações para espécies medicinais em região de restinga (MEDEIROS; FONSECA; ANDREATA, 2004; SOUZA; ARAÚJO; SANTOS, 2007).

Das espécies mais citadas, o mastruz (C. ambrosioides) e a jurubeba (S. paniculatum) estão presentes na Relação Nacional de Plantas de Interesse ao Sistema Único de Saúde (RENISUS) (BRASIL, 2009), bem como a cidreira/macineira (L. alba), o campim-santo (Cymbopogon sp.) e também a jurubeba (S. paniculatum) estão presentes na lista de plantas medicinais regulamentadas pela Agência Nacional de Vigilância Sanitária (ANVISA) (BRASIL, 2010), que traz orientações gerais para uso medicinal doméstico das plantas.

Em 2016 a Política Nacional de Plantas Medicinais e Fitoterápicos completou 10 anos. No mesmo ano foi publicado "Memento Fitoterápico da Farmacopeia Brasileira” (ANVISA, 2016), a fim de orientar os profissionais na prescrição dessa terapêutica. Nesse sentido, entende-se que o mercado 
de fitoterápicos no Brasil irá crescer e, potencialmente, o PAE São Sebastião pode ampliar a exploração desses recursos - tanto os cultivados quanto os que ocorrem naturalmente na região - por meio do beneficiamento e comercialização das espécies que são indicadas para o uso no Sistema Único de Saúde (SUS).

\section{c. Místico-religiosas, Ornamentais, Artesanato e Outros usos}

Apenas 10 espécies se enquadraram no tipo de uso Místico-religioso. As espécies mais utilizadas foram: vassorinha (11, Scoparia dulcis), fedegoso (10, Senna obtusifolia) e pinhão-roxo (9, Jatropha curcas). O número de citações total de espécies para esta categoria foi semelhante para homens e mulheres, respectivamente, 17 e 22 citações. O baixo número de espécies não parece ser diferente ao encontrado na literatura em áreas de restinga, visto que nos estudos de Melo, Lacerda e Hanazaki (2008) e Fonseca-Kruel e Peixoto (2004) esta categoria nem mesmo se faz presente.

Para esta categoria verificou-se ainda a indicação de apenas três tipos de uso (reza, benzimento e benzimento contra mau-olhado) e de duas partes da planta (inteira ou ramo). Isso pode ser explicado pelo fato de que, na localidade, não foi encontrado nenhum curandeiro/rezador que detivesse maiores conhecimentos em relação ao uso das plantas místico-religiosas, assim, apenas as espécies e ritos mais "comuns" são conhecidos da comunidade. Ressalta-se também que alguns moradores deram a entender durante os diálogos que nem mesmo utilizam dessas plantas para essa finalidade, com expressões como "minha mãe dizia que usava o camarão" (M20, 47 anos) ou "o povo diz que usa vassorinha e velane pra benzê contra olhado... Eu mesma não ligo" (M9, 53 anos) - indicando que o traço cultural relativo a esse uso está sendo perdido e/ou substituído.

Para a categoria Ornamentais foram indicadas cinco espécies. Destas, três foram citadas apenas por homens: boa noite/bom dia (Catharanthus roseus), cabeça-de-frade (Melocactus zehntneri) e tipi (Petiveria alliacea), no entanto, com números de citação muito baixos (respectivamente 3, 1 e 1), o que pode indicar discordância em relação aos demais entrevistados. Isso é interessante, visto que o cuidado com a casa por meio de "enfeites" é geralmente atribuído às mulheres, e estas não recordaram dessas espécies como sendo ornamentais e, sim, indicaram apenas a palmeira (Dypsis lutescens, com 12 citações, o que equivale a 60\% das mulheres entrevistadas) e o comigo-ninguém-pode (Dieffenbachia sp., com 7 citações, ou 35\% das entrevistadas). Nesta categoria ocorreu o uso de nomes diferentes para designar uma mesma espécie devido a um fator visual específico: coloração diferenciada das flores - assim, para os homens, bom dia/boa noite são a espécie $C$. roseus, diferenciadas pelas colorações branca/rosa, respectivamente. 
Para a categoria Artesanato foram indicadas três espécies, a saber: ouricuri ( $S$. coronata), tabua (Typha sp.) e imbé (Philodendron acutatum). O uso do imbé (P. acutatum) foi relatado por apenas um dos assentados, o H11 de 59 anos, que é de origem de um povoado no estado de Alagoas, o que confirma a visualização durante a pesquisa de que esse recurso não é utilizado com esse fim nem no PAE São Sebastião nem no povoado vizinho. A tabua (Typha sp.) foi indicada apenas por homens, que afirmaram que o uso da espécie ocorre tradicionalmente em um povoado próximo (Povoado Macaco, município de Pacatuba). É muito provável que as mulheres não tenham citado esse recurso, primeiramente, por trabalharem exclusivamente com a palha do ouricurizeiro no PAE, e por terem menos mobilidade que os homens desde o nascimento - já que as mulheres são em sua maioria do povoado Alagamar e os homens do município de Pacatuba. O ouricurizeiro (S. coronata) foi citado por todos os homens (19) e todas as mulheres (20) entrevistados como matéria-prima para o artesanato, refletindo mais uma vez sua importância socioeconômica-cultural local.

Para a categoria Outros usos, as quatro espécies citadas foram indicadas para: 1) vence tudo (Justicia sp.): abortivo para mulheres; 2) babatenã (Inga sp.): medicinal animal, para lavagem de feridas; 3) nim (Azadirachta indica): inseticida e medicinal animal (para lavagem de feridas); 4) pulga de burro/cabacinha (Luffa operculata): medicinal animal, para fortalecer. Todas as espécies desta categoria (com exceção da pulga de burro com 7 citações) foram muito pouco citadas, o que pode indicar o seu desuso paulatino por parte da população. Quanto ao tratamento dos animais, por exemplo, os moradores afirmaram que já há vacinação periódica e alguns até mesmo adicionam remédios industrializados na ração do gado e de equinos.

\section{Conclusão}

Os moradores do PAE São Sebastião detiveram maior conhecimento de espécies enquadradas nas categorias de uso Alimentícia e Medicinal. Além de serem as mais citadas, a importância das espécies nativas para a comunidade ficou evidente também através do alto valor de uso (VU) atribuído a espécies como ouricurizeiro e mangabeira, evidenciando a relevância dos recursos advindos da restinga para a alimentação e a atividade econômica local.

Também ficou evidente que há outras espécies que podem ter o potencial de uso melhor explorado, a fim de complementar a alimentação familiar e a renda dos moradores, particularmente, espécies nativas exploradas mediante o extrativismo, tais como cambuí e cambucá, que podem ser exploradas na categoria Alimentícia, bem como a jurubeba, que pode ser explorada na categoria 
Medicinal. Com a valorização do conhecimento local sobre essas espécies, agregado a um investimento relacionado ao estabelecimento de exploração em bases sustentáveis e beneficiamento in loco de subprodutos, é possível reforçar o caráter agroextrativista do PAE São Sebastião.

Assim, conclui-se que mediante a fragilidade do ecossistema em que o PAE São Sebastião se insere e o caráter da proposta diferenciada desse assentamento, faz-se necessário que novos estudos tragam enfoques relativos às espécies com maior pressão de uso, às preferências de introdução de espécies exóticas e/ou de extrativismo de nativas e os possíveis impactos sobre a flora regional, apontando e construindo coletivamente novas alternativas viáveis para o manejo sustentável dos recursos florísticos em assentamentos agroextrativistas.

\section{Agradecimentos}

À CAPES, pela bolsa de Mestrado concedida ao primeiro autor; à equipe de profissionais do ASE - Herbário da Universidade Federal de Sergipe, pelo zelo com o material de pesquisa; à comunidade estudada, pela colaboração essencial à construção deste trabalho.

\section{Referências}

ALBUQUERQUE, U. P. de. Introdução à etnobotânica. Recife: Bagaço, 2002.

ALBUQUERQUE, U. P. de. et al. How ethnobotany can aid biodiversity conservation: reflections on investigations in the semi-arid region of NE Brazil. Biodiversity and Conservation, v. 18, p.127$150,2009$.

ALBUQUERQUE, U. P. de; LUCENA, R. F. P. de; ALENCAR, N. L. Métodos e técnicas para coleta de dados etnobiológicos. In: ALBUQUERQUE, U. P. de; LUCENA, R. F. P. de; CUNHA, L. V. F. C. da. (Orgs.). Métodos e técnicas na pesquisa etnobiológica e etnoecológica. Recife: NUPPEA, 2010. p. 41-64.

ALMEIDA, A. W. B. de. Amazônia: a dimensão política dos "conhecimentos tradicionais". In: ACSELRAD, H. (Org.). Conflitos ambientais no Brasil. Rio de Janeiro: Relume Dumará, 2004. p. 37-56.

AMOROZO, M. C. de M.; VIERTLER, R. B. A abordagem qualitativa na coleta e análise de dados em etnobiologia e etnoecologia. In: ALBUQUERQUE, U. P. de; LUCENA, R. F. P. de; CUNHA, L. V. F. C. da. (Orgs.). Métodos e técnicas na pesquisa etnobiológica e etnoecológica. Recife: NUPPEA, 2010. p.67-82. 
BOSCOLO, O. H.; Valle, L. de S. Plantas de uso medicinal em Quissamã, Rio de Janeiro, Brasil. Iheringia, Série Botânica, Porto Alegre, v. 63, n. 2, p. 263-277, 2008.

BRASIL. Conselho Nacional de Saúde. Resolução 196, de 10 de outubro de 1996. Disponível em <http://www.ee.usp.br/pesq/doc/resolucao_196-96.pdf>. Acesso em: $1^{\text {o nov. }} 2011$.

. Instituto Brasileiro dos Recursos Naturais e Renováveis. Decreto n 96.999, de 20 outubro de 1998. Regulamenta a criação da Reserva Biológica de Santa Isabel.

. Lei n⿳0 9.985, de 18 de julho de 2000. Institui o Sistema Nacional de Unidades de Conservação e dá outras providências. Disponível em: 〈http://www.planalto.gov.br/ccivil_03/leis/19985.htm>. Acesso em: 12 mar. 2015.

. Lei no 11.428, de 22 de dezembro de 2006. Dispõe sobre a utilização e proteção da vegetação nativa do Bioma Mata Atlântica, e dá outras providências. Disponível em: <http://www.planalto.gov.br/ccivil_03/_Ato2004-2006/2006/Lei/L11428.htm>. Acesso em: 10 dez. 2011.

. Ministério da Saúde. Direção de Administração e Finanças. Secretaria de Ciência, Tecnologia e Insumos Estratégicos. Renisus - Relação Nacional de Plantas Medicinais de Interesse ao SUS. 2009. Disponível em: <http://portalsaude.saude.gov.br/index.php/cidadao/principal/agenciasaude/noticias-anteriores-agencia-saude/3487>. Acesso em: 26 mar. 2014.

Agência Nacional de Vigilância Sanitária (Anvisa). Lista de fitoterápicos regulamentados pela Anvisa. Brasília: Anvisa, 2010. Disponível em: <http://g1.globo.com/Noticias/Brasil/2010/03/drgvege.pdf>. Acesso em: 27 mar. 2014.

Agência Nacional de Vigilância Sanitária (Anvisa). Memento fitoterápico da farmacopeia brasileira. Brasília: Anvisa, 2016.

CARTAXO, S. L.; SOUZA, M. M. de A.; ALBUQUERQUE, U. P. de. Medicinal plants with bioprospecting potential used insemi-arid northeastern Brazil. Journal of Ethnopharmacology, v. 131, n.2, p.326-342, 2010.

CASTRO, E. Território, biodiversidade e saberes de populações tradicionais. In: DIEGUES, A. C. (Org.). Etnoconservação: novos rumos para a conservação da natureza. São Paulo: Hucitec, Nupaub/USP, 2000. p. 165-182.

FONSECA-KRUEL, V. S. da; PEIXOTO, A. L. Etnobotânica na Reserva Extrativista Marinha de Arraial do Cabo, RJ, Brasil. Acta Botânica Brasilica, v. 18, n. 1, p. 177-190, 2004.

GANDOLFO, E. L.; HANAZAKI, N. Etnobotânica e urbanização: conhecimento e utilização de plantas de restinga pela comunidade nativa do distrito do Campeche (Florianópolis, SC). Acta Botanica Brasilica, v. 25, n. 1, p. 168-177, 2011.

INTERNACIONAL SOCIETY OF ETHNOBIOLOGY (ISE). 2006. Internacional Society of Ethnobiology Code of Ethics (with 2008 additions). Disponível em: <http://ethnobiology.net/codeof-ethics/>. Acesso em: 11 mar. 2015. 
MELO, S.; LACERDA, V. D.; HANAZAKI, N. Espécies de restinga conhecidas pela comunidade do Pântano do Sul, Florianópolis, Santa Catarina, Brasil. Rodriguésia, v. 59, n. 4, p. 799-812, 2008.

MEDEIROS, M. F. T.; FONSECA, V. S. da; ANDREATA, R. H. P. Plantas medicinais e seus usos pelos sitiantes da Reserva Rio das Pedras, Mangaratiba, RJ, Brasil. Acta Botânica Brasílica, v. 18, n. 2, p. 391-399, 2004.

MIRANDA, T. M.; HANAZAKI, N. Conhecimento e uso de recursos vegetais de restinga por comunidades das ilhas do Cardoso (SP) e de Santa Catarina (SC), Brasil. Acta Botânica Brasílica, v. 22, n. 1, p. 203-215, 2008.

MOTA, D. M. da.; SANTOS, J. V. dos. Uso e conservação dos remanescentes de mangabeira por populações extrativistas em Barra dos Coqueiros, estado de Sergipe. Acta Scientiarum. Human and Social Sciences, v. 30, n. 2, p. 173-180, 2008.

OLIVEIRA, D. M. de; SANTOS, L A. S.; GOMES, L. J. Espécies madeireiras de uso combustível em área de restinga, Pirambu, Sergipe, Brasil. Interações (Campo Grande), v. 14, n. 1, p.115-123, jun. 2013.

Uso dos quintais no Assentamento Agroextrativista São Sebastião, Pirambu. In: OLIVEIRA, D. M. et al. (Orgs.). Usos, percepções, instrumentos de gestão e sustentabilidade da flora do estado de Sergipe. São Cristóvão: Editora UFS, 2014. p.15-41.

PASA, M. C.; SOARES, J. J.; GUARIM NETO, G. Estudo etnobotânico na comunidade de Conceição-Açu (alto da bacia do rio Aricá Açu, MT, Brasil). Acta Botânica Brasilica, v. 19, n. 2, p.195-207, 2005.

PEREIRA, E. O. Populações extrativistas e reforma agrária no estado de Sergipe: o caso do povoado Alagamar. In: CURADO, F. F. Do plural ao singular: dimensões da reforma agrária e assentamentos rurais em Sergipe. Aracaju: Embrapa Tabuleiros Costeiros, 2008. p. 167-199.

PORTO, P. R. M. Situação florestal do estado de Sergipe e subsídios para um plano de recomposição. Dissertação (Mestrado em Desenvolvimento e Meio Ambiente) - Programa de Pós Graduação em Desenvolvimento e Meio Ambiente, Universidade Federal de Sergipe, São Cristóvão, Sergipe, 1999.

PULIDO, M. T. et al. Home gardens as an alternative for sustainability: challenges and perspectives in Latin America. In: ALBUQUERQUE, U. P. de; RAMOS, M. A. (Ed.). Current topics in ethnobotany. Kerala, India: Research signpost, 2008. p. 55-80.

REFLORA. Programa REFLORA/CNPq. Lista de Espécies da Flora do Brasil. 2015. Disponível em: <http://floradobrasil.jbrj.gov.br/jabot/listaBrasil/PrincipalUC/PrincipalUC.do>. Acesso em: 09 jun. 2015.

RIZZINI, C. T. Tratado de Fitogeografia do Brasil: aspectos ecológicos, sociológicos e florísticos. São Paulo: Âmbito Cultural, 1997.

RUFINO, M. U. de L. et al. Conhecimento e uso do ouricuri (Syagrus coronata) e do babaçu (Orbignya phalerata) em Buíque, PE, Brasil. Acta Botânica Brasilica, v. 22, n. 4, p. 1141-1149, 2008. 
SANTOS, L. L. dos et al. Técnicas para coleta e processamento de material botânico e suas aplicações na pesquisa etnobotânica. In: ALBUQUERQUE, U. P. de; LUCENA, R. F. P. de; CUNHA, L. V. F. C. da. (Orgs.). Métodos e técnicas na pesquisa etnobiológica e etnoecológica. Recife: Nuppea, 2010. p. 277-296.

SECRETARIA DE PLANEJAMENTO DE SERGIPE (SEPLAN/SE). Atlas Digital sobre Recursos Hídricos de Sergipe. Aracaju: Seplan/SE, 2011.

SILVA, V. A. da et al. Técnicas para análise de dados etnobiológicos. In: ALBUQUERQUE, U. P. de; LUCENA, R. F. P. de; CUNHA, L. V. F. C. da. (Orgs.). Métodos e técnicas na pesquisa etnobiológica e etnoecológica. Recife: Nuppea, 2010. p. 187-206.

SOUZA, C. G.; ARAÚJO, B. R. N. de; SANTOS, A. T. P. dos. Inventário Etnobotânico de Plantas Medicinais na Comunidade de Machadinho, Camaçari-BA. Revista Brasileira de Biociências, Porto Alegre, v. 5, n. 1, p.549-551, jul. 2007.

SOUZA, R. M.; OLIVEIRA, A. C. A. Risco ambiental nos Sistemas Dunares de Aracaju. In: ARAÚJO, Hélio Mário de et al. (Org.). O ambiente urbano: visões geográficas de Aracaju. São Cristóvão: Departamento de Geografia da UFS, 2006. p. 181-195.

Artigo recebido em 19/11/2017. Aceito para publicação em 17/01/2018. 